\title{
Correspondence
}

\section{Deficiency of argyrophilic neurones in the myenteric plexus as cause of intestinal obstruction}

Sir,

In the November issue of the Archives (1976, 51, 837), Tanner and co-workers published their article on the distribution of argyrophilic neurones in the myenteric plexus in cases of functional intestinal obstruction. The data concerning autonomic nerve cells reported in this study are dependent upon the silver procedure and it is unfortunate that the authors have failed to state, other than in a legend, which method was used in their investigation. Since the techniques which use silver salts to demonstrate autonomic nerves are prone to technical failure and are notorious in producing nonspecific staining of other tissue elements, such as collagen and elastic fibres, a detailed description of the methodology (and an indication of control techniques) must be provided if the results reported by these workers are to be critically assessed.

Concerning the functional implications which these workers have proposed for their findings, it would have been of value to have applied one of the relatively specific neurohistochemical techniques to the material at their disposal. The latter methods provide results whose functional implications are far more significant than those which can be derived using silver impregnation techniques alone. In our view, more evidence than that which is presented in this paper must be provided before the authors' claim of a deficiency of intramural neurones causing functional intestinal obstruction can be accepted.

ROBERT H. ANDERSON
Department of Paediatrics,
Cardiothoracic Institute,
Brompton Hospital,
London.
JOHN A. GOSLING
Department of Anatomy,
University of Manchester,
Stopford Building,
Oxford Road, Manchester M13 9PT.

Dr Tanner and associates comment:

The methodology of the silver technique was not given in detail because it would have taken up considerable space and this was not considered appropriate in a clinical journal. However, a reference should have been given and we apologize for its omission. It is Schofield, G. C., (1960), Brain, 83, 490. We do not agree that silver methods are prone to failure, and in competent hands they produce quite consistent results. Better results are obtained by keeping the material in the hands of a single experienced technician than by putting it through the routine laboratory. This is true of many neuropathological techniques which require a lot of attention to detail-not only silver stains. The problems of connective tissue staining are minimal when viewed under the microscope or reproduced in colour, though black and white photography is less satisfactory, because the dark brown and black tend to become indistinguishable.

We entirely agree that it would be highly desirable to study the gut in this syndrome histochemically, as well as pharmacologically and electrophysiologically. Indeed, we hope that by drawing attention to this problem, other cases will be recognized early, and the opportunity taken to examine surgical specimens of the bowel thoroughly by all relevant techniques. Unfortunately, only formalin-fixed material was available from our cases. Nevertheless, in a syndrome in which peristalsis is grossly and persistently abnormal, and in which careful and controlled study fails to show neurones which stain with silver, it does seem reasonable to attribute the defective function to the morphological abnormality.

M. S. TANNER, BARBARA F. SMITH, and JUNE K. LLOYD Department of Child Health, King's College Hospital Medical School, Denmark Hill, London SE5 8RX.

\section{Decreased reverse triiodothyronine $\left(\mathrm{RT}_{3}\right)$ concentration in amniotic fluid in fetal hypothyroidism}

Sir,

It has been hypothesized that a reduced concentration of $\mathrm{RT}_{3}$ in the amniotic fluid may be the best biochemical indicator for antenatal detection of congenital hypothyroidism (Chopra and Crandall, 1975; Fisher, 1975; Meinhold et al., 1976). To our knowledge this hypothesis has not yet been verified because congenital hypothyroidism is a fairly rare and usually unforeseeable disease. However, we recently showed that temporary hypothyroidism in the newborn could result from amniofetography (AFG) performed on the mother at the end of pregnancy (Rodesch et al., 1976). This form of hypothyroidism was attributed to blocking of the fetal thyroid by excess iodide (Vagenakis and Braverman, 1975). Such a situation seemed to afford suitable conditions for studying $\mathrm{RT}_{3}$ in the amniotic fluid for the purpose of antenatal detection of hypothyroidism.

We determined the concentration of $\mathrm{RT}_{3}$ and iodide in the amniotic fluid before AFG and several times in the hours and days after the examination in 4 pregnant women. The concentration of $\mathrm{RT}_{3}$ was determined by specific radioimmunoassay without extraction, by the techique used for serum (Vigneri et al., unpublished data) adapted for amniotic fluid. All the measurements were taken in triplicate during each assay; the intra-assay variation coefficient was $4 \%$. Iodide was determined by the method of Barker et al. (1951). 


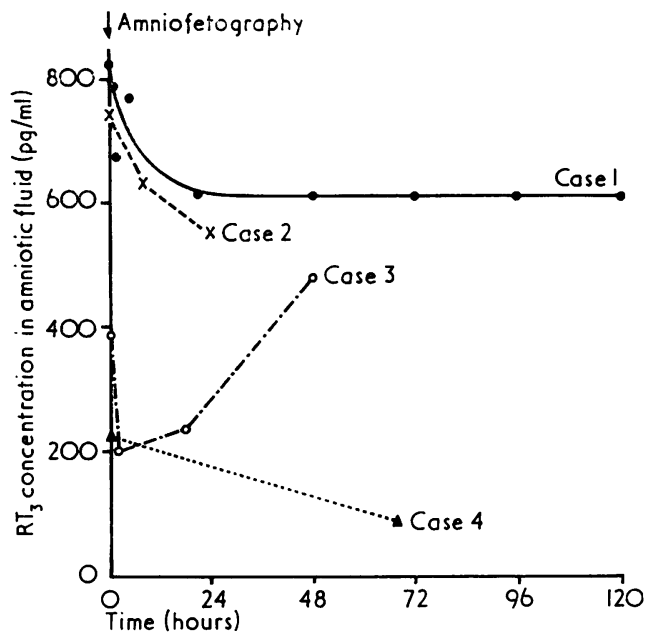

Fig. Evolution of $R T_{3}$ concentration in amniotic fluid before (Time 0 ) and after amniofetography.

The results are given in the Fig. Starting levels of $\mathrm{RT}_{3}$ before injection varied between 220 and $820 \mathrm{pg} / \mathrm{ml}$. These very variable values lie within the normal range reported by other authors (Chopra and Crandall, 1975; Meinhold et al., 1976). As the Fig. shows, the level of $\mathrm{RT}_{3}$ in the amniotic fluid fell conspicuously in all 4 cases in the hours after the AFG. In one case (no. 3) the change was short-lived. The maximum drop in relation to the starting level ranged from $26 \%$ to $64 \%$. Such a drop is highly significant $(P<0 \cdot 005)$. The iodide concentrations in the amniotic fluid in 3 cases before AFG were 0.010 , 0.033 , and $0.900 \mathrm{mg} / 100 \mathrm{ml}$. When the $\mathrm{RT}_{3}$ levels were lowest, the iodide concentrations stood at the extremely high levels of 214,120 , and $290 \mathrm{mg} / 100 \mathrm{ml}$, respectively. In the case where the iodide concentration was the highest (Case 3) the level of $\mathrm{RT}_{3}$ had already fallen substantially after 30 minutes.

The births took place respectively at 20 hours (Case 2), 2 days (Case 3), 3 days (Case 4), and 13 days (Case 1) after AFG. The level of thyroid stimulating hormone (TSH) was measured in the newborns on the 5th day of life according to the method used for the systematic detection of congenital hypothyroidism (Delange et al., 1977). In 3 out of 4 cases TSH was greatly increased $(51 \cdot 0,48 \cdot 0$, and $51 \cdot 0 \mu \mathrm{U} / \mathrm{ml}$, compared with the normal value $( \pm$ SEM) of $1.7 \pm 1.0 \mu \mathrm{U} / \mathrm{ml}$ ); such values are characteristic of congenital hypothyroidism. In Case 2 the level of TSH was normal $(7 \cdot 0 \mu \mathrm{U} / \mathrm{ml})$; this is probably explained by the very short lapse of time between AFG and birth. Later, the TSH levels spontaneously returned to normal except in Case 1 in which thyroid extract treatment was applied.

These findings show that AFG causes a significant drop in the level of $\mathrm{RT}_{3}$ in the amniotic fluid. In 3 out of 4 cases the newborns presented very high TSH levels on the fifth day of life, characteristic of hypothyroidism. Decreased $\mathrm{RT}_{3}$ in the amniotic fluid therefore constitutes a reliable indicator of fetal hypothyroidism.

The very high iodide concentrations observed in the amniotic fluid suggest that this hypothyroidism is indeed due to blocked intrathyroidal organification of iodine (Wolff and Chaikoff, 1948; Vagenakis and Braverman, 1975). This mechanism would also account for the transitory nature of the hypothyroid condition.

In our observations only the progressive decrease of $\mathrm{RT}_{3}$ in the amniotic fluid indicated the presence of fetal hypothyroidism. The $\mathrm{RT}_{3}$ concentration in itself did not allow such a diagnosis because of the variability of physiological levels of $\mathrm{RT}_{3}$ in the amniotic fluid. None the less, it seems highly probable that in prolonged fetal hypothyroidism the concentration will be sufficiently low to permit a diagnosis on that basis alone.

This work was supported in part by grant No.3.45553. 75 of the 'Fonds de la Recherche Scientifique Médicale' Belgium.

S. FILETTI, M. CAMUS, F. RODESCH, F. DELANGE R. VIGNERI, and A. M. ERMANS Department of Endocrinology, University of Catania, Italy, and Departments of Radioisotopes, Obstetrics and Pediatrics, University of Brussels, Hopital SaintPierre, 322 rue Haute, 1000-Brussels, Belgium.

\section{References}

Barker, S. B., Humphrey, M. J., and Soley, M. H. J. (1951). Clinical determination of protein-bound iodine. Journal of Clinical Investigation, 30, 55-62.

Chopra, I. J., and Crandall, B. F. (1975). Thyroid hormones and thyrotropin in amniotic fluid. New England Journal of Medicine, 293, 740-743.

Delange, F., Camus, M., Winkler, M., Dodion, J., and Ermans, A. M. (1977). Serum thyrotrophin determination on day 5 of life as screening procedure for congenital hypothyroidism. Archives of Disease in Childhood, 52, 89-96.

Fisher, D. A. (1975). Reverse tri-iodothyronine and fetal thyroid status. New England Journal of Medicine, 293, 770-772.

Meinhold, H., Wenzel, K. W., Dudenhausen, J. W., and Saling, E. (1976). Reverse triiodothyronine and thyroxine in amniotic fluid. European Thyroid Association. Seventh Annual Meeting, Helsinki, June 1976. Abstract No. 28. Acta Endocrinologica, 82, Suppl. 204.

Rodesch, F., Camus, M., Ermans, A. M., Dodion, J., and Delange, F. (1976). Adverse effect of amniofetography on fetal thyroid function. American Journal of Obstetrics and Gynecology, 126, 723-726.

Vagenakis, A. C., and Braverman, L. E. (1975). Adverse effects of iodides on thyroid function. Medical Clinics of North America, 59, 1075-1088.

Wolff, J., and Chaikoff, I. L. (1948). The inhibitory action of excessive iodine upon the synthesis of diiodotyrosine and of thyroxine in the thyroid gland of the normal rat. Endocrinology, 43, 174-179. 